\title{
El papel de las mujeres en el desarrollo de la agricultura urbana: el caso de la «Red de agricultura ecológica huertos en línea»
} \\ karla.solari@unmsm.edu.pe \\ Jazmín Goicochea Medina \\ jazmin.goicochea@unmsm.edu.pe \\ Mishel Huamán Nakamura \\ mishel.huamna@unmsm.edu.pe \\ Ronaldiño Tamara Pachas \\ ronaldino.tamara@unmsm.edu.pe
}

\begin{abstract}
RESUMEN
En el presente artículo $^{2}$ analizamos el papel de las mujeres en la promoción y desenvolvimiento de la agricultura urbana (AU) en dos distritos de Lima Sur: San Juan de Miraflores y Villa María del Triunfo. Estas experiencias se encuentran enmarcadas en el proyecto de responsabilidad social: «Red de agricultores ecológicos huertos en línea» de la empresa Red de Energía del Perú, y serán analizadas de forma transversal por el sistema sexo/género.
\end{abstract}

Palabras clave: rol de las mujeres; agricultura urbana; sistema sexo/género.

\section{The women's role in urban agriculture development. The case of «Ecological agriculture network online vegetable gardens»}

\begin{abstract}
This article analyze the rol of women in the promotion and development of urban agriculture in two districts of South Lima: San Juan de Miraflores and Villa Maria del Triunfo. These experiences are framed in the social responsibility project: «Network of organic farmers, online vegetable gardens» of the Red de Energía del Perú company, and will be analyzed transversally by the sex / gender system.
\end{abstract}

KEYwORDs: role of women; urban agriculture; sex / gender system.

Es necesario aclarar que existe participación masculina en el proyecto, sin embargo, el número de participantes es menor con relación a la participación femenina.

2 Agradecemos a Mario Vásquez Layza y a Lucero De la Rosa Tapia por su valiosa colaboración en trabajos que sirvieron de base para la elaboración de este artículo. 


\section{Introducción}

Bonito trabajamos en el huerto, me divierto, me converso hay estamos y nos ayudamos entre nosotros... Nilda Bejarano, socia del huerto Paracas

E l espacio donde se desarrolla nuestra investigación son dos distritos del Sur de Lima, los cuales integran la periferia urbana de la ciudad, por ende, consideramos pertinente iniciar hablando sobre el acelerado crecimiento de las ciudades. El informe "World Urbanization Prospects» de Naciones Unidas (2015) nos dice que la población urbana a nivel mundial registrada en 1950 era de 746 millones, en aproximadamente seis décadas este grupo poblacional aumento hasta 3.9 billones de habitantes. Latinoamérica es una de las regiones con mayor población viviendo en ciudades, sin embargo, el crecimiento de estas urbes ha sido marcada por la desigualdad (da Cuhna, 2009). El crecimiento demográfico, la desigualdad socioeconómica y la tímida planificación urbana de la región han dado como resultado la expansión de las periferias urbanas.

Este proceso de urbanización conlleva desafíos socio ecológicos, económico sociales y políticos, donde una de las principales preocupaciones está relacionada a la seguridad alimentaria en las urbes. Frente al explosivo crecimiento de la ciudad y la incapacidad del mercado para absorber toda la fuerza de trabajo, las personas buscan formas alternativas para la reproducción de la vida; es en este contexto que la agricultura urbana contribuye al empleo, los medios de subsistencia, la nutrición y la capacidad de recuperación del medio ambiente (Degenhart, 2016).

El fenómeno de la agricultura urbana ha sido materia de investigación de agrónomos y urbanistas, los cuales han dejado una importante contribución en sus campos de estudio y praxis (Barraza, 2015). Uno de los puntos más importantes de esta actividad es su orientación, ya que estas acciones locales parten desde una perspectiva que prioriza la autonomía alimentaria y que constituyen una alternativa a la producción económica hegemónica (Jiménez, 2016) . A pesar de que no se puede brindar una única definición sobre agricultura urbana, consideramos que el concepto de Luc Moougeot ${ }^{3}$, recogido por el Programa de Gestión

3 Mougeot: «Urban Agriculture: Definition, Presence, Potentials and Risks», tomado de Degenhart (2016). de las Naciones Unidas ONU-Habitat, es adecuado para los fines del artículo:

La agricultura urbana está ubicada dentro (intraurbana) o en la periferia (periurbana) de un pueblo, una ciudad o una metrópoli, y cultiva o cría, procesa y distribuye una diversidad de productos alimentarios y no alimentarios, (re)utilizando en gran medida recursos humanos y materiales, productos y servicios que se encuentran en y alrededor de dicha zona, y a su vez provee recursos humanos y materiales, productos y servicios en gran parte a esa misma zona urbana.

A partir de este punto, es esencial que agreguemos una variable adicional al estudio de la experiencia de agricultura urbana, este es el sistema sexo/género. Tomamos el siguiente concepto de Gayle Rubin (1996) para decir que este sistema es:

El conjunto de disposiciones por el que una sociedad transforma la sexualidad biológica en productos de la actividad humana y en el que se satisfacen esas necesidades humanas transformadas. (...) Sistema de sexo/género, por otra parte, es un término neutro que se refiere a ese campo e indica que en él la opresión no es inevitable, sino que es producto de las relaciones, sociales específicas que lo organizan.

En este concepto el género es transversal a la sociedad, el cual traduce una característica biológica (gónadas masculinas o femeninas) en un conjunto de valores, normas, comportamientos y roles, los cuales a pesar de estar naturalizados desde la interacción cotidiana hasta los marcos estructurales, sería erróneo pensarlos como estático, puesto que los procesos sociales les brindan movimiento y resignificación.

La variable género en la agricultura urbana, antes ha sido objeto de estudio. Por un lado tenemos los trabajos que resaltan que las mujeres a través de esta actividad ganan participación en espacios no domésticos. Como por el ejemplo el trabajo Género y agricultura de Hovorca et al. (2004) el cual nos dice que la agricultura urbana es un medio donde las mujeres pueden realizar prácticas importantes sin descuidar las tareas domésticas, les proporciona un espacio de interacción en el ámbito público, las ayuda a desarrollar actitudes organizativas, además esta actividad puede ser una fuente de ingresos. Por otro lado, la 
investigación de Fernando Neira (2004) nos brinda otra perspectiva que entra en debate con la anterior mencionada, al exponernos la siguiente paradoja: aunque las mujeres involucradas en la agricultura urbana logren cierta autonomía gracias a esta actividad, esta autonomía podría estar acompañada por una excesiva carga laboral que no les permitiría ejercerla a plenitud.

En esta investigación nos abocaremos específicamente a describir cómo es que el sistema sexo/ genero, transversal en la agricultura urbana del caso estudiado, se desenvuelve en la experiencia de la "Red de agricultores ecológicos huertos en línea» ${ }^{4}$. El cual está localizado en dos distritos del Sur de Lima, San Juan de Miraflores y Villa María del Triunfo. Específicamente, en la zona de servidumbre donde se encuentran las torres de alta tensión a cargo de la empresa Red de Energía del Perú (REP). Este proyecto integra el trabajo de las socias y socios ${ }^{5}$ (los cuales invierten dinero, tiempo y esfuerzo), la ayuda material y la concesión del espacio por parte de la empresa REP, el asesoramiento y certificación de organizaciones no gubernamentales (ONG) como IPES o IDMA, además del reconocimiento (en el caso de Villa María del triunfo) o ausencia (caso de San Juan de Miraflores) de los gobiernos locales.

La metodología utilizada en el proceso de investigación fue netamente cualitativa, se utilizaron las herramientas de entrevistas a profundidad y de historias orales con las y los miembros del huerto y entrevistas semiestructuradas con actores externos al huerto.

La presentación de la investigación está dividida en cinco partes: La primera aborda la memoria y la constitución de los huertos, la segunda explora la organización y las relaciones internas desenvueltas en el marco de los mismos, la tercera da cuenta de las dinámicas externas, la cuarta está dedicada a las perspectivas a futuro y la última parte hace referencia a las reflexiones finales. Todas ellas atravesadas por la pregunta de investigación: ¿Cuál es el papel de las mujeres en el desarrollo de la agricultura urbana de los huertos en línea?

4 Es necesario aclarar que existe participación masculina en el proyecto, sin embargo, el número de participantes es menor con relación a la participación femenina.

5 Con esta denominación se caracterizan las mujeres y hombres que participan en el trabajo de los huertos.
Agradecemos a las compañeras y a los compañeros de los huertos Paracas y Pampas de San Juan, con los que hemos venido dialogando y aprendiendo de sus conocimientos y experiencias.

\section{Memoria y constitución de los huertos}

La promoción de la agricultura urbana está transformando las ciudades físicamente como en lo que a interacción interpersonal se refiere. Hombres y mujeres se desenvuelven como agricultores, aunque en estas experiencias analizadas son las mujeres quienes en su mayoría han asumido el reto de enverdecer el desierto de Lima Sur. Por ejemplo, en el huerto Paracas de los doce (12) sub-huertos, nueve (9) de ellos están bajo la responsabilidad de a las mujeres. Una situación similar encontramos en el huerto de Pampas de San Juan, donde de las veintidós (22) sub-huertos, quince (15) son trabajados por socias.

La señora María Morales Verde, ex-coordinadora del Huerto Paracas, nos manifiesta cómo es que nace la iniciativa:

inició el 2004, nació... un tiempo vino una ONG llamada CEPES, en colegio primero vino y estaba capacitando a mamás,... yo no tenía pequeñitos. Ellos han pensado invitar a los comités a las trabajadoras sociales de seis comités y nos capacitó dos ańos, luego nosotros invitamos más... primero practicamos en nuestras casas, luego bajamos aquí, ya luego vino la seńora Gregoria y empieza con fuerza.

Ambas experiencias de AU, al ser parte del mismo proyecto, comparten una serie de elementos comunes. El primero, es que las experiencias están íntimamente ligadas al espacio en donde se desarrollan, es así que podemos ver que los dos huertos, se caracterizan por lo siguiente: albergar amplias zonas de desmonte, no tener acceso al agua (solo en el caso de San Juan) y tener suelos áridos y salitrosos. Lo segundo, es que la formación de estas experiencias de agricultura urbana están enmarcadas en un contexto más amplio a nivel de Lima Sur impulsado por diversas ONG como IPES, CEPES, DESCO y FOVIDA, los cuales articularon a los actores clave de estas zonas de Lima (REP, gobiernos locales y ciudadanos) para hacer posible que se implemente el enfoque de agri- 
cultura urbana en espacios amplios. Por último, estas experiencias han buscado integrar a grupos vulnerables (madres solteras, desempleados y adultos mayores) de las zonas aledañas a la red de servidumbre de la Red de Energía. En función a ello, narraremos el proceso de constitución de cada uno de los huertos, partiendo de los aciertos y dificultades que se han presentado.

\section{Proceso de constitución del huerto en linea Paracas}

Su constitución ha pasado por diferentes etapas que ha comprometido a distintas entidades tanto públicas como privadas. Es necesario mencionar como antecedente el trabajo del Centro Peruano de Estudios Sociales (CEPES). En el año 2002 CEPES realiza un proyecto con un grupo de personas (en su mayoría mujeres pertenecientes al comedor popular de la zona) para fomentar la creación de huertos en las viviendas.

Primeramente la idea de huertos nació de la reunión con una institución, de CEPES, y nos formó a las 8 personas y nos convocaba a las reuniones $y$ las charlas, de ahí nació la iniciativa. En mi casa había practicado, poco a poco. (Nilda Bejarano)

Aunque esta primera experiencia fue bien recibida y practicada, terminó fragmentándose porque la organización dependía de CEPES y cuando esta se fue, no se logró mayor cohesión y se desintegró. Sin embargo, esta inicial experiencia no va a ser fácilmente olvidada debido a que la zona en la que se había trabajado era un área descampada, un espacio público altamente excluyente y peligroso para las mujeres y sus hijos e hijas, como agrega la señora María Morales: «Eso era un desierto, daba miedo de andar, por los drogos». En ese sentido, existía una necesidad latente por rescatar dicho espacio.

En el año 2005, la REP comienza a impulsar un trabajo en las zonas de la red de servidumbre a través de líderes locales, quienes tenían experiencia en promoción del desarrollo y habían sido capacitadas. María Morales coordinadora del huerto Paracas, comenta que al principio fue difícil, pues solo se había acondicionado la primera parte del huerto. El primer huerto en formarse se llamó «Julián Carabi», con el tiempo y la constante participación fue formándose los demás huertos como Paracas y Saccsayhuaman. Dos años después la zona además de estar limpia y acondicionada para la agricultura urbana, se encontraba ya con los productos sembrados y también con cosechas muy diversas. Como nos cuenta la señora María, la gente se fue uniendo debido a que la experiencia de trabajar en los huertos es bastante reconfortante, a cambio del tiempo y el trabajo invertido reciben no solo los productos, sino también una sensación de bienestar, lo que los motiva a seguir trabajando en el huerto: «Yo paraba enferma, y el huerto bastante me ha hecho a recuperar mi salud, me siento alegre».

Este esfuerzo de los pobladores por rescatar la zona y producir en los huertos junto con el trabajo articulador de las ONG antes mencionadas con el gobierno local y la empresa, se gestiona el reconocimiento de los huertos con la Ordenanza No 021-2007 de fortalecimiento de la agricultura urbana como una actividad permanente y legítima en el distrito, lo que le brinda ciertos beneficios como la entrega gratuita del agua, lo que es, a diferencia del segundo Huerto a analizar, una ventaja considerable.

\section{Proceso de constitución del Centro de Capacitación Piloto Huertos en Linea Pampas de San Juan}

En el 2004 la Municipalidad de San Juan de Miraflores envía una invitación a varios líderes vecinales para participar en un foro sobre experiencias de proyectos que se habían realizado en diferentes partes del mundo en promoción del desarrollo. Uno de los productos de esta actividad era que los participantes presenten una idea de proyecto, es entonces que la seńora Doraliza presenta la idea de rescatar la pampa próxima a su casa, debido a que este espacio estaba ocupado de desmonte y basura, dicho espacio era un punto de convergencia para el consumo de droga y la delincuencia (desde asaltos hasta violaciones), en suma, representaba un peligro para la comunidad tanto en materia de sanidad como de seguridad. En sus propias palabras:

Anteriormente esto [por la pampa] estaba lleno de basura y desmonte, no había nadie que liderara un plan... lo más importante es la pampa porque había asaltos, invasiones, drogos... Quería que nos apoyen para terminar con esa basura y delincuencia en esta área». 
Pasaron tres años hasta que, en el 2007, la Red de Energía de Perú junto a IPES se presenten en la zona para iniciar el proyecto de rescate de la pampa, que es el área donde se encuentran las antenas, por medio de los huertos agroecológicos. La Sra. Doraliza nos cuenta que organizar a la gente para que se sume a participar en el proyecto fue difícil, en ese primer momento ella no recibe apoyo de la mayoría de la población aledańa (solo 4 personas se llegan a inscribir). Luego de unos años y con un grupo más consolidado se realizan trabajos para limpiar el área de la pampa donde se desarrollarían los huertos, la limpieza de la basura y el desmonte comprometió un trabajo en conjunto de algunos vecinos y de todos los miembros (y sus familiares) que querían participar en el proyecto, tuvieron que poner sus propios esfuerzos para limpiar la pampa, ya que la municipalidad había descuidado esa zona:

La municipalidad no apoya, encima deja desmonte y basura, por ejemplo, ahorita está ahí el camión de la municipalidad (señalando un camión de basura que estaba estacionado al frente). Felizmente hemos podido salvar este terreno, estamos haciendo algo para la vida. [Milton Zatalaya]

Después de la limpieza hecha por los pobladores, se inicia el sembrado con la formación de cuatro parcelas, los cuales se enfrentan a la dificultad de traer agua desde sus casas (debido a que el huerto no cuenta con un punto de agua y en esa época el camión cisterna no ingresaba a la zona próxima al huerto). Pero pese a la limpieza realizada, la presencia de basura continuaba y es en el 2010 que se logra un mejor recojo de desperdicios mediante la contratación, de parte de los socios y pobladores interesados en apoyar, de un cargador frontal. Además unos años después se consigue que un camión cisterna se acerque lo suficiente al huerto para abastecer a los socios y socias. El agua es muy importante, ya que Lima es su mayor parte un desierto, invertir en agua puede ser lo bastante caro como para observar que en las épocas de verano algunos huertos trabajados por mujeres se encuentren abandonados, esto porque a diferencia de los hombres quienes cuenta con otras fuentes de ingresos que les permiten comprar agua suficiente, ellas no poseen esos recursos. Esto puede marcar un punto álgido en la participación.
Esta es la única experiencia de huertos en línea de San Juan de Miraflores, debido a que la empresa cuenta con solo una responsable para conectarla con las organizaciones, la presencia de la REP en Pampas de San Juan es menos tacita, si a esto le agregamos que el gobierno local no contribuye al desarrollo de la agricultura urbana, podemos ver que esta experiencia cuente con más obstáculos que la anterior. Sin embargo, que los huertos aun permanezcan puede ser explicado gracias a la participación de las mujeres. Actualmente ya no se cuenta con una presidenta, sin embargo, durante su proceso de constitución fue una lideresa la que asumió un rol clave de organización, así como también las socias realizan los trabajos de promoción de productos, participando activamente en ferias y capacitaciones. A pesar de no estar en los espacios de toma de decisión su rol es clave para el sostenimiento y avance de los huertos. Aunque una consecuencia de no estar en los espacios de toma decisión es que los obstáculos a los que ellas se enfren$\tan$ (como costear el agua y el abono) no son integrados a los problemas generales a los que se enfrenta el huerto para garantizar su sostenibilidad.

\section{Organización y relaciones internas}

Estas particularidades descritas en el proceso de formación de los huertos han tenido incidencia en sus relaciones internas y a nivel organizativo. El huerto Paracas es el huerto con mayor antigüedad y cuenta con reconocimiento del gobierno local. Ha logrado establecer una organización definida con menores espacios de conflictividad. Siendo el representante del huerto, el Coordinador/a; le siguen el secretario/a de actas y secretario/a de economía. Por su parte, el huerto Pampas de San Juan tiene una estructura organizativa similar, en donde el representante es el presidente y se ańaden dos coordinadoras internas que tienen como finalidad monitorear la producción del huerto. En esta última, si bien los cargos están establecidos en su estatuto, sus representantes no son activos. Aún más, las diferencias personales entre lideresas dentro del huerto dificultan el cumplimiento de sus responsabilidades como representantes.

A pesar de las especificaciones de cada huerto, comparten elementos propios de organizaciones sociales de base: la asamblea de socios es la máxima ins- 
tancia de decisión, todos y todas pueden participar y decidir, y se sujetan a las decisiones tomadas en ella. Así, todo asunto relacionado con el huerto debe ser conocido por la asamblea de socios. Nuestra participación también cursó este proceso, ya que los socios y socias decidieron aceptar nuestro acercamiento en una asamblea.

Como se hizo mención en el proceso de formación de los huertos, las acciones desplegadas por las socias han sido vitales para sostener la experiencia de agricultura urbana, incluso, teniendo la mayor cantidad de puestos directivos en sus respectivos huertos. Sí bien en la actualidad (desde el año 2016) existe una paridad de hombres y mujeres en las secretarías de ambos huertos, siendo los representantes de mayor cargo los varones, las socias han son quienes les dan base e impulso a los huertos.

Esto se refleja en las actividades y eventos que realizan dichos huertos. Por describir un ejemplo, en la primera jornada de agricultura urbana realizado en el Centro de Agricultura Urbana Paracas en Villa María del Triunfo, las socias fueron quienes participaron en mayor número y de forma activa. Esta mayoría femenina participó en la venta de productos y platos gastronómicos, en el diálogo de experiencias, relacionándose con otras organizaciones y en la enseñanza sobre la agricultura urbana.

Asimismo, la participación activa de las socias se traduce en el logro de lazos y relaciones con otras organizaciones porque son ellas quienes tienen dichos vínculos, de la mano de su presidente o coordinador. Ellas han logrado concretar ventas de sus productos en empresas panaderas cercanas. Cómo nos cuenta la socia del huerto Pampas de San Juan, Emilia Rodas:

Nosotras hemos logrado conseguir clientes, por ejemplo la panadería. Personalmente yo me acerque con el dueño y como le he cumplido. Le he dicho que son acelgas orgánicas y ha aceptado comprar de más socios. Un día los de la REP han visitado la panadería para que escuchen nuestros clientes (2016)

De igual forma, algunas socias del Huerto Paracas llevan sus productos al comedor popular aledaño a sus parcelas con el objetivo de no desperdiciar su producción y favorecer a sus vecinos. Ellas han vinculado ambos espacios de participación para que de comple- menten. Así nos cuenta la ex coordinadora del huerto Paracas, María:

Cuando no hay mucha venta o sobran acelgas, cebollas chinas, lechugas los llevamos al comedor para que las asociadas cocinen (2016).

Las socias, también, cumplen otra labor interesante en cada organización, la enseñanza. En ambos huertos, dado sus experiencias y capacitaciones en la práctica de la agricultura urbana, ellas han acumulado saberes, las cuales comparten a sus compańeros y compañeras nuevas. Así, en un primer momento, la práctica de la agricultura urbana agroecológica se genera en ambos huertos con el acompańamiento y autoconocimiento entre las y los socios. Esta forma de aprendizaje se complementa con el apoyo de la REP, quienes brindan apoyo técnico. En sí, en la cotidianidad las socias y socios utilizan lógicas de ayuda mutua, a pesar de las diferencias personales que existan dentro del huerto.

Por parte de sus pares masculinos en la organización y convivencia diaria describen una participación igualitaria. Recuerdan que las parcelas son por familias y que cada uno se encarga de hacerlo producir. Para ellos, cada quien cumple su labor y todos son responsables del futuro del huerto. No consideran que únicamente sean las mujeres quienes brinden sostenibilidad al huerto, sino cada socio/socia contribuye con su participación. Sin embargo, lejos de particularidades, las socias son parte de este sistema sexo-género que las estructuran en su cotidianidad.

Siendo los roles que se establecen entre hombres y mujeres como componentes de sus propias relaciones internas, Esto se pudo sentir cuando uno de los socios más antiguos del huerto Pampas de San Juan, mientras trabajaba en una parcela vecina, mencionó que estaba haciendo divisiones de la parcela por el pedido de una socia porque «esos trabajos lo tenemos que hacer los hombres, (que) es un trabajo para hombres, si ellas nos piden hay que hacerlo. Ya lo hice antes para otras vecinas».

Las actividades mismas que desempeñan las mujeres en el sostenimiento y mejora de sus huertos muestran los dispositivos de género. En las ferias y actividades de integración son las mujeres a quienes se les encarga la preparación de platos gastronómicos y bebidas. Si bien estos espacios permiten mayor 
participación femenina, las condiciona a estas actividades, sin que sus pares masculinos intervengan o se dediquen a otras actividades.

También la procedencia de las socias en ambos huertos es un aspecto importante para reconocer el papel preponderante de las mujeres en estas experiencias. Las socias de ambos huertos son, en su mayoría, migrantes andinas de la época del conflicto armado interno. Escaparon de la marginación y violencia sufrida en sus lugares de origen y se asentaron en la periferia de la ciudad. Pero, es ahí donde encuentran "condiciones restrictivas del mercado de trabajo y del mercado en general y es, de nuevo, marginalizada, esta vez definitivamente» (Quijano, 1977, p. 118). Así, sin las condiciones para hacerlo, se ven limitadas en el acceso al trabajo calificado y se dedican a labores domésticas, ligadas a ellas o al comercio local.

Así, las mujeres han impulsado estos esfuerzos bajo marcos sociales de división sexual del trabajo, condiciones de marginación y desvaloración del trabajo femenino, y limitaciones estatales que afectan su bienestar. Logrando que estas prácticas reproduzcan cotidianamente su vida social e individualmente su «mundo de la reproducción de la vida cotidiana tenga ámbitos más locales»; no ligados necesariamente a una lógica de mercado. Como mencionan Claudia Cabrera y Marcela Vio (2014):

los actores de la economía popular desarrollan estrategias de trabajo y supervivencia [...] que favorezcan algunos elementos que son fundamentales en el proceso de la formación humana, como la socialización del conocimiento y de la cultura, la salud, la vivienda, etc. (p. 37).

\section{Dinámicas externas e impacto de los huertos en la población vecina}

Ya nos hemos acostumbrado nosotros a hortalizas, a comer cosa sana, si no nos ayudan tenemos que buscar ayuda en otro sitio, conjuntamente con mis compañeras, tenemos que luchar por nuestro sustento.

María Morales Verde

Socia del huerto de Paracas

Parte de esos vínculos, tratados en el punto anterior, es que las relaciones externas confluyen con en las internas y ,que en nuestro caso, cumplen un papel fundamental en el proceso de hacer realidad la iniciativa de agricultura urbana, evidenciando que el papel de las mujeres es esencial en esta actividad, debido al tiempo disponible y a la dedicación en el proceso de construcción de los huertos. Ciertamente, el tiempo y la dedicación que pusieron en este proyecto se debe a que han estado relegadas a lo doméstico, sin acceder al mercado formal, por ello con mayor tiempo disponible y con la necesidad de salir de romper su papel histórico como mujeres, romper con las cadenas de lo privado.

Históricamente, las mujeres hemos sido segregadas por nuestra condición biológica, es decir, por ser mujeres, y aún más por ser mujeres de sectores populares y de procedencia provinciana. Es decir, somos atravesadas por nuestro género, clase y procedencia. En esta situación se encuentran las mujeres que visibilizamos en este estudio, pero que han encontrado una salida en la agricultura urbana.

Ellas viven en distritos periféricos y en contextos de marginalidad frente al mercado global que va absorbiendo todo a su paso, sin embargo también es posible la existencia de nuevas formas de construir lo cotidiano, desde las múltiples identidades y culturas que se vinculan en un mismo territorio, allí donde los tentáculos de la economía global no han alcanzado, los márgenes de la ciudad (Sassen, 2007).

Sin embargo, desde sus territorios y sus actividades, las mujeres y sus huertos, han tenido que vincularse con una serie de instituciones, como la Red de Energía del Perú (REP), una empresa global que ha sido parte del proceso de construcción de los huertos que analizamos. La REP es una empresa que transmite energía, especializándose en la construcción, operación y mantenimiento de redes de transmisión de energía eléctrica en alta tensión y, como es obligatorio en nuestro país, tiene como parte de su organigrama un área de responsabilidad social que vela por la calidad de vida de sus empleados, familias y la sociedad en general, teniendo como principio transversal la preservación del medio ambiente. En el marco del programa de desarrollo que la empresa desenvuelve se encuentra el vínculo con los huertos de San Juan de Miraflores y Villa María del Triunfo.

La REP cumple con el programa de responsabilidad social al brindar el espacio a los vecinos y vecinas de los distritos mencionados, cabe señalar que 
este vínculo busca cubrir las necesidades tanto de la empresa como de la población. La empresa necesita que este terreno no sea invadido el tiempo que dure la concesión, es decir, la población que se encuentra en los huertos soluciona el problema de la empresa, cuidando el territorio. A su vez, la población genera otras formas de subsistencia a partir de la agricultura urbana. Bajo esa lógica la REP ha venido brindando algunos materiales, semillas, incluso compra la producción. Además, ofrece capacitaciones, se involucra en la gestión de puntos de agua, entre otras cosas.

En el camino, las y los participantes de los huertos notaron que el territorio no era suficiente, sino que también era necesaria una certificación agroecológica que avale los costos y calidad ecológica de los productos. La ONG Promoción del Desarrollo Sostenible (IPES) ha venido desenvolviendo un trabajo dirigido a la certificación con previas capacitaciones sobre los insumos y herramientas a usar, ya que es una organización que tiene como eje principal la seguridad alimentaria y nutricional, a partir de la construcción de ciudades ambiental, social y económicamente sostenibles. Sin embargo, a pesar del soporte técnico, los miembros de los huertos se ven obstaculizados debido a la inversión que requiere sembrar productos orgánicos. Por un lado, los hombres debido a los diversos ingresos que perciben pueden costear en mayor medida estos gastos. Por otro lado, las mujeres ${ }^{6}$ se ven limitadas porque no han logrado vincularse a algún empleo y percibir otros ingresos que sustenten los gastos que implica sembrar orgánicamente.

Las ONG - como ya se mencionó- intervienen en organizaciones ubicadas en periferias y que contengan poblaciones vulnerables vinculadas a sus líneas de trabajo, como es el caso de los huertos. Es por eso que no solo IPES generó un vínculo con los huertos, sino otras instituciones como IDMA, quienes también han trabajado en la certificación, pero contratados por la REP.

Hasta el momento hemos descrito las relaciones con organizaciones privadas con sus propios intereses, sin embargo, los huertos también han establecido relación con el Estado, en este caso con la Municipalidad. La relación que mantienen es un

6 Algunas mujeres del huertos han logrado insertarse en algunas actividades laborales, como Doraliza que trabaja como seguridad fuera de un colegio cercano al huerto. Sin embargo, el sueldo es bastante reducido. tanto conflictiva, a pesar de que en América Latina, las Municipalidades ${ }^{7}$ vienen cumpliendo un papel impulsor.

La situación del huerto de Villa María del Triunfo denota que la relación con la municipalidad se ha restringido al reconocimiento y actividades bastante concretas que no impulsan otras iniciativas. La relación empieza con la publicación de la Ordenanza $\mathrm{N}^{\circ}$ 021-2007-MVMT en la que reconoce a la agricultura urbana como una actividad legítima y permanente en el distrito, luego desde el municipio se han organizado ferias para la venta de sus productos, además les brinda acceso a provisiones de agua y capacitación a cargo de la Subgerencia de Ornato, Parques y Jardines - Programa Municipal «Agricultura Urbana» Biohuertos agroecológicos ${ }^{8}$.

El caso del huerto de San Juan de Miraflores es mucho más precaria, ya que no existe reconocimiento e incluso la municipalidad intento apropiarse del terreno que ha sido prestado por la REP a los y las pobladoras que impulsaron el huerto. Es evidente que luego de este incidente los miembros del huerto desconfían de la municipalidad.

Sin embargo, en ambos casos las municipalidades han ubicado pequeños toldos a los extremos de los huertos en los que se dedican a la Agricultura Urbana.

Hemos anotado la relación de organizaciones tanto privadas como públicas con los huertos, sin embargo, no es suficiente porque no podemos omitir la relación con la comunidad, con los y las vecinas, quienes ven con buenos ojos la iniciativa de agricultura urbana porque han significado la recuperación de un terreno abandonado que albergaba un gran flujo de contaminación debido al desmonte y delincuencia debido a la poca iluminación, es decir, solucionaron dos problemas: seguridad y sanidad.

La relación con la población aledańa no se reduce a la recuperación de espacios públicos, sino también a que han generado un vínculo con los huertos porque quieren ser parte de la organización o porque les in-

\footnotetext{
7 Según la Revista de Agricultura Urbana (2001), los municipios en América Latina tienen como propósito fortalecer la seguridad alimentaria, así como enfrentar la pobreza y cuidar el medio ambiente, la salud y la mayor participación de la población. Es así que vienen impulsando políticas contemplando a la agricultura urbana como estrategia municipal para una gestión urbana más sostenible.

8 La relación con esta institución está teñida de desconfianza, por el beneficio político que deja evidencia el encargo de esa institución en los huertos (los miembros del huerto han etiquetado de "mentiroso» al representante de la municipalidad).
} 
teresa consumir los productos, por ejemplo, algunas familias ${ }^{9}$ vienen acercándose a los socios y socias para preguntar si es posible integrar aun la organización, ya que las socias ofrecen los productos a sus vecinos y vecinas. Otra forma de relación de la población con los huertos se encuentra en el comedor popular —ubicado en Villa María del Triunfo-, esto debido a que algunas socias también participan de comedores populares ${ }^{10}$, además los y las socias donan sus productos al comedor para que la comunidad pueda beneficiarse al consumirlos.

Los huertos se constituyen con el objetivo de subsistencia, es así que observamos cómo se intenta colocar ${ }^{11}$ los productos en el mercado, sin embargo, el problema son los precios, pues al ser productos orgánicos implican mayor costo, a su vez, mayor precio de venta, lo que implica mayor dificultad de encontrar espacios de intercambio que comercialicen estos productos. Entendemos, a partir de esto, que los productos se direccionan hacia sectores sociales con mayor capacidad de gasto. Los productos restantes se redireccionan tanto para consumo personal como para el comedor - en el caso de Villa María del Triunfo- como ya veníamos mencionando.

Cabe señalar que todas estas dinámicas han sido dirigidas por las mujeres miembros de los huertos en línea de la mano sus socios hombres y los distintos actores mencionados. Por un lado IPES ha venido generando un soporte logístico, incluso, anímico para concretar el proyecto. A su vez, la aceptación y participación de los vecinos y vecinas de la zona ha implicado sostener el proyecto, pues algunas familias compran también lo producido en los huertos, además del consumo en el comedor como en el caso de Villa María del Triunfo, la señora María venía siendo la coordinadora del huerto de Paracas así como del comedor. Si bien la señora María ya no es coordinadora del huerto de Paracas, es una de las personas que ha venido impulsando e integrando esta iniciativa. Así como, en Pampas de San Juan, la señora Doraliza (ex coordinadora) sigue teniendo un papel importante en la organización de los huertos en línea.

9 En un principio no confiaban en el desenvolvimiento de esta iniciativa, incluso algunas personas que venían participando se retiraron.

10 La coordinadora del huerto de Paracas es también coordinadora del comedor popular.

11 En mayor medida son las mujeres las que intentan colocar los productos en el mercado debido a su tiempo disponible para gestionarlo, además de la necesidad de recibir ingresos.
Tras mirar estas experiencias de agricultura urbana manifestada en los huertos, evidenciamos que actualmente en las ciudades que habitamos existen formas particulares de enfrentar la pobreza y la desigualdad que genera nuestra sociedad capitalista. En nuestro caso, las mujeres enfrentan estos problemas que las aquejan de una forma peculiar, como mencionan Hovorca, van Veenhuizen \& Wilbers (2004), la agricultura urbana va a significar para las mujeres desenvolverse organizadamente en un ámbito público y, sobretodo, les va a permitir generar ingresos, dándole un vuelco al sistema sexo/género imperante. Es decir, es evidente que las mujeres han asumido un papel determinante en el desenvolvimiento de esta actividad, usando como estrategia su condición de segregación a lo privado. Pues bien, aunque las dinámicas capitalistas se encuentren alrededor de esta iniciativa (lo que podría derivar a una absorción de esta actividad a la lógica de mercado y hacerla parte de una mera dinámica de intercambio comercial), la capacidad de agencia y lo que representa para estas mujeres los huertos hace que la iniciativa signifique resistencia frente a las formas hegemónicas de relacionamiento. Esto puede reflejarse en que su organización va más allá de la búsqueda de ganancia, es más bien la reproducción ampliada de la vida que se visibiliza en el rescate de un espacio en abandono, la puesta en valor de su trabajo diario en los huertos y la producción de alimentos saludables, lo prioritario.

\section{Perspectivas de futuros}

Prosiguiendo con nuestro análisis, es necesario conocer las perspectivas de futuro de las mujeres en la promoción y su desenvolvimiento en la agricultura urbana de los huertos en línea de San Juan de Miraflores y de Villa María del Triunfo, para esto es necesario reconocer las dinámicas de centralidad y marginalidad reproducen las desigualdades ya existentes, pero que también permite originar una dinámica especifica de las formas actuales de crecimiento económico (Sassen, 2009). Es así, que conociendo su constitución, su organización, sus relaciones internas y externas, y haciendo hincapié en su papel como mujeres en el desarrollo de la agricultura urbana, podemos recalcar que sus perspectivas futuras giran principalmente en torno a sus propias problemáticas relacio- 
nadas a la dificultad de encontrar un empleo sin descuidar sus labores domésticas, asimismo, la apuesta por la agricultora en terreno desértico y eriazo suele ser en ambas experiencias muy costoso. Es por eso, que bajo el propio testimonio de las socias principalmente, como forma de alivianar estas dificultades se proyectan a futuro seguir replicando la experiencia de los Huertos en Línea en sus hogares cuando termine la concesión del terreno (en sus jardines específicamente) reflejando una forma alternativa para la reproducción de la vida y un medio de subsistencia en sus hogares para los años futuros.

Mira, si nos quitan el terreno, que podemos hacer, si nos han hecho firmar un compromiso. Yo haría mi huerto en mi casa, yo ya sé todos los secretos (Nilda Bejarano, Huertos Paracas).

Asimismo, suele surgir una cierta tensión potencial, ya que, si bien las socias aceptan que ese terreno no les pertenece, consideramos que estas mismas han ido formando una fuerte identidad con la parcela donde cultivan, lo cual puede dificultar a futuro, retirarse del espacio concesionado, ya que les ha implicado mucho trabajo y sacrificios. Ahora bien, las socias más antiguas de los Huertos manifiestan muchas ansias de poder compartir sus conocimientos a otras mujeres que deseen replicar estas experiencias. Tienen como proyecto a largo plazo, capacitar a otras mujeres para que puedan aprender los conocimientos de la agricultura urbana y que pueda ser una opción de emprendimiento para que puedan contribuir económica y nutricionalmente en sus hogares, de esta manera el papel de estas socias se va haciendo más evidente dentro de su hogar, comunidad y en los diferentes espacios públicos.

De igual modo, el desconcierto con respecto a la tenencia del agua, es un punto preocupante que afecta a las socias en su desenvolvimiento en la promoción de la agricultura urbana, por ejemplo, en el caso de los Huertos de Pampas San Juan, este recurso tan esencial para sus cultivos todavía tiene que ser comprado con sus propios recursos. Socias sean adultas mayores y no suelan laborar bajo un salario intensifica la dificultad. Si bien en el huerto de Paracas cuentan con puntos de agua gracias al reconocimiento y al impulso que la Municipalidad de Villa María del Triunfo le ha brindado, hay fechas que no cuentan con agua en el huerto debido al descuido de trámites administrativos y presupuestales del gobierno local (la falta de pago del agua). Además, que el hecho de que la mayoría de las para pagar y acceder al agua. La seguridad de tener agua para sus cultivos es latente y esencial en ambos huertos hacia un futuro ya que el no tenerla podría llevar a que estas mujeres abandonen la experiencia en la agricultura urbana.

Ya tenemos casi dos años, gestionando que nos reconozcan como asociación para que nos faciliten los puntos de agua, eso nos perjudica mucho (Doralisa, Huerto Pampas San Juan).

De la misma forma, para seguir fortaleciendo el papel de las mujeres en el desarrollo de la agricultura urbana, desde ya y como parte de su futuro se hace necesaria la apertura de mercados. Como avance las socias de los Huertos en Línea cumpliendo con su rol en la promoción de sus cultivos, constantemente están en búsqueda de agentes estratégicos que puedan brindarles mercado para que ellos puedan vender sus productos agroecológicos. ANPE y la plataforma de "Agricultura Urbana en Lima», aparecen justamente en este contexto para brindarles impulso a la venta de cultivos mediante ferias agroecológicas en diferentes lugares de Lima y en sus propios huertos. Asimismo, las agricultoras y los agricultores desean que sus cultivos también pueden llegar a sus mercados locales, si bien cuentan con algunos clientes desean que los consumidores puedan saber la riqueza de los productos agroecológicos y que muchas personas puedan seguir consumiendo más, la señora Nilda Bejarano manifiesta:

A veces nos dicen en el mercado, está muy caro tu berenjena, está muy caro tu rabanito, déjame a precio para vender, pero se le tiene que explicar que estos cultivos no tienen pesticida es todo natural, eso lo hace más sano para la salud.

Podemos decir, que un escenario futuro que ellas consideran precisamente es el fuerte fortalecimiento de su organización y una verdadera cohesión entre socias y socios, para esto, el presidente del Huerto Paracas y el presidente del Huerto Pampas de San Juan recalcan que es vital seguir impulsando iniciativas dentro de su asociación a favor de la agricultura 
urbana y la equidad de oportunidades. Esto sucede debido a que, como cualquier grupo humano, suelen surgir conflictos que si no son solucionados de manera correcta y colectivamente puede resquebrajar los lazos de apoyo que se tiene en la asociación. Claramente, Arocena (2002) nos revela que es necesario para fortalecer esta cohesión, poder entender que la identidad de un grupo humano será mucho más fuerte, mucho más capaz de generar dinámicas colectivas si el grupo ha podido superar dificultades, si ha sido capaz de transformar amenazas en cartas de triunfo, si ha obtenido victorias sobre factores adversos. Para esto, cada una de las socias y socios recalcan que también es necesario obtener una asesoría especializada y constante, por eso, consideran como un escenario prometedor, el trabajo con universidades como la UNTECS, Universidad Nacional Mayor de San Marcos, Universidad Autónoma, Universidad Nacional Agraria La Molina, las cuales han tenido un contacto con los agricultores, si bien no han sido a profundidad, hay ciertos compromisos pendientes entre estudiantes y agricultores de los huertos por motivos de investigación, proyectos sociales, proyectos ambientales, que hoy por hoy están siendo facilitados por la plataforma de «Agricultura Urbana en Lima» y por ANPE. Finalmente, se hace necesario el mejoramiento o creación de normativas a favor de la agricultura urbana donde se destaque, proteja y valore el rol que las mujeres cumplen en la producción de alimentos y la generación de bienestar, riqueza y desarrollo como en los casos de estas experiencias en Villa María del Triunfo y San Juan de Miraflores.

\section{Conclusión}

Ahora volvamos a repasar algunos aspectos claves de estas dos experiencias teniendo en cuenta que el sistema sexo/género es transversal al estudio. El primero tiene que ver con ciertos elementos con los que deben de contar los proyectos de las ONG para ser financiados. Deben de encontrarse en zonas periféricas, trabajar con un tema que los financistas o empresas consideren de suma importancia (como la seguridad alimentaria) y por sobre todo, trabajar con grupos vulnerables que sean capaces de dar sostenibilidad a la experiencia. Es así que las mujeres de zonas periféricas se vuelven en un grupo clave, no son parte del mercado laboral formal, muchas son madres solteras y tienen experiencia en llevar adelante actividades comunitarias, tienen lo necesario para ser consideradas como grupos vulnerables a los que hay que atender en un proyecto, pero a la vez tienen las capacidades para darle continuidad a las actividades. Con respecto a la vulnerabilidad, debemos de entender esta no como inherentes a ellas sino como parte del sistema sexo/genero de nuestra sociedad, el cual ha asignado un rol domestico para las mujeres, pero además las ha excluido del mercado de trabajo asalariado, por ende su vulnerabilidad es producto de las relaciones sociales.

Por ende, el sistema sexo/género no puede ser soslayado, sino que debería ser empleado como una herramienta analítica esencial para desentrañar las complejidades de las actividades agrícolas urbanas en estos espacios, siendo así debemos de tomar en cuenta que si las mujeres tienen un mayor grado de participación también se debe a que la mayoría de ellas es ama de casa, y antes de estar vinculadas con esta actividad estaban desempeńando otras labores ya sea en los comedores populares u otras actividades que en última instancia siguen siendo labores domésticas. Este es el caso de la seńora Nilda Bejarano, quien nos comenta: «A veces como trabajan los varones, tarde llegan... yo me dedico los sábados y los domingos y cuando esta para cosechar, limpiar yo me dedico sola, sola me doy tiempo».

Un caso muy distinto es del señor Juan Cervantes Cucho, que se encuentra trabajando en el huerto de Pampas San Juan que, antes de dedicarse a la agricultura urbana, trabajaba como técnico en soldaduras, quien nos manifiesta lo siguiente: «Si yo me dedico a esto, es porque me gusta... por eso he dejado mi trabajo, porque me gusta y desde pequeño, cada vez que veía a mis padres yo les ayudaba».

Otro punto fundamental es que la zona al ser un descampado es un punto referente de inseguridad, pero con un enfoque de género aplicado a la percepción de inseguridad podemos decir son las mujeres, los niños y niñas quienes quedan más expuestos a la criminalidad en espacios abandonados. Este es uno de los motivos clave para que las mujeres decidan brindar su tiempo y trabajo al huerto, ya que su esfuerzo contribuye a una apropiación positiva del espacio público por medio de la agricultura urbana. Vemos que esta organización económico popular, 
comprendido en su mayoría por mujeres, trasciende la lógica de la ganancia y se vincula a la reproducción ampliada de la vida (Cabrera y Vio, 2014).

Un elemento que diferencia a las dos experiencias es la desigualdad de oportunidades entre hombres y mujeres para permanecer como agricultores orgánicos. Mientras que en Paracas el gobierno local garantiza el agua para la agricultura, en Pampas de San Juan son los mismos socios y socias las que deben de costear estos precios. Y aunque estas cuenten con más tiempo para participar en diversas actividades, son los hombres quienes en su mayoría al tener otras fuentes de recursos pueden sobrellevar de mejor forma los obstáculos relevantes como la escasez de agua y el suelo salitroso que necesita de nutrientes.

Es evidente que el papel de las mujeres en la iniciativa de agricultura urbana analizada ha sido determinante, a pesar de los límites que las aquejan por su situación. Recordemos que fueron mujeres quienes impulsaron la iniciativa y que además gastaron tiempo y dinero en las distintas gestiones para la implementación de los huertos en línea. A pesar de su situación socioeconómica lograron impulsar este proyecto, debido a dos cuestiones: la necesidad de subsistencia y la necesidad de romper con las cadenas de lo privado. Los huertos en línea han permitido que se organicen no solo por una cuestión económica, sino también por una cuestión anímica.

Asimismo, los testimonios afirman que el trabajo en esta actividad les brinda una sensación de bienestar, recordemos que Hovorca et al. (2004) consideran que la agricultura urbana es un medio para que las mujeres puedan participar en actividades más allá del ámbito doméstico en la ciudad. Este trabajo las lleva a incursionar de un modo singular fuera de la esfera privada, lo que contribuye a su sensación de bienestar. Esto es importante, porque nos ayuda a atisbar que el trabajo doméstico no remunerado que ellas desenvuelven en sus hogares no les causa bienestar. Podríamos especular, por ejemplo, que tales grados de malestar pueden ser generados por la explotación que servir a otros sin compensación ni reconocimiento y de forma obligatoria puede generar en la vida de las mujeres.

En ese sentido, los casos de estudio que visibilizamos ponen sobre la berma de lo denominado público los problemas privados de las mujeres de sectores populares como la situación de segregación a lo domés- tico, la poca facilidad de acceso al mercado laboral formal para las mujeres. Es decir, podemos señalar que la agricultura urbana es una forma de resistir frente a los obstáculos que el sistema capitalista y el sistema sexo/género imperante le imponen.

Por último, es importante considerar los desafíos que deben de afrontar estas mujeres en el desarrollo de la agricultura urbana a futuro. Primero, el tema del acceso al agua se hace vital hacia un futuro ya que el no tenerla podría llevar a que estas mujeres abandonen la experiencia en la agricultura urbana y el obtener su punto de agua es la principal prioridad. Otro desafío va relacionado a seguir sumando a mujeres para que conozcan de la experiencia de la agricultura, para esto se hace necesario la capacitación y las iniciativas de cada una de ellas.

\section{Bibliografía}

Arocena, J. (2002). El desarrollo local: un desafío contemporáneo. Uruguay: Taurus - Universidad Catedrática. Recuperado de http://cebem.org/cmsfiles/publicaciones/Arocena_resumen.pdf.

Barraza, V. (2015). Centro de investigación en agricultura urbana Barrios Altos - Cercado de Lima. Repositorio Académico Universidad San Martín de Porres. Recuperado de http://www.repositorioacademico. usmp.edu.pe/bitstream/usmp/1446/1/barraza_sve.pdf

Cabrera, C., \& Vio, M. (2014). Los hilos de la economía popular en la posconvertibilidad. En C. Cabrera, \& M. Vio, La trama social de la economía popular (pp. 37-42). Buenos Aires: Espacio Editorial.

Chuspe, K., Ňañez, C., Benites, O., \& Soria, C. (2017). La economía social y solidaria de la BioFeria de Miraflores. Investigaciones Sociales, 345-354.

Coraggio, J. L. (2011). Territorio y economías alternativas. En J. L. Coraggio, Economía social solidaria: el trabajo antes que el capital (pp. 277-327). Quito: Ediciones Abya-Yala.

Coraggio, J. (2016). La Economía Social y Solidaria: niveles y alcances de sus actores. El papel de las universidades. En C. Puig (coord.), La Economía Social y Solidaria: conceptos, prácticas y políticas públicas (pp. 1540). Universidad del País Vasco, HEGOA.

da Cunha, J., \& Rodríguez Vignoli, J. (2009). Crecimiento urbano y movilidad en América Latina. Revista Latinoamericana de Población, 3 (4- 
5), 27-64. Recuperado de http://www.redalyc.org/ $\mathrm{html} / 3238 / 323827368003 /$

Degenhart, B. (2016). La agricultura urbana: un fenómeno global. Nueva Sociedad, 133-146. Recuperado de https://dialnet.unirioja.es/servlet/ articulo? codigo $=5434044$

Dennis Escudero, D., \& Perú, O. d. (2010). Lima, Perú. En FAO, La Agricultura Urbana y Periurbana en América Latina y el Caribe:Compendio de estudios de casos (pp. 177-220). FAO.

Hovorca, A., van Veenhuizen, R., \& Wilbers, J. (2004). Género y Agricultura. Revista de agricultura Urbana, www.ruaf.org.

JiménEZ, N. (2016). La nueva independencia: de la huerta urbana a la autonomía alimentaria. Las luchas sociales por la tierra en América Latina: Un análisis histórico, comparativo y global, 135-140.

Morales, F., Montes, A., \& Salva, M. (2010). Desarrollo de la agricultura urbana en los suburbios del este de Lima. XIV International Congress on Proyect Emgineering. Lima (Perú).

Muños, R. (2011). Alcances y desafíos de la economía popular urbana. Reflexiones a partir de análisis sectoria- les y casos de estudio de la Región Metropolitana de Buenos Aires. Ciudades en transformación, 337-355.

Neira, F. (2005). Participación laboral y autonomía femenina en un contexto de agricultura urbana. Estudios Demográficos y Urbanos, vol. 20, núm. 3, México D.F, pp. 533-567. Recuperado de http://www.redalyc.org/ articulo.oa? $\mathrm{id}=31220304$

Quijano, A. (1977). Dependencia, urbanización y cabio social en Latinoamérica . Lima: Mosca Azul Editores.

SÁnchez Aguilar, A. (2011). PERÚ: Migración Interna reciente y el Sistema de Ciudades 2001-2007. Lima: INEI.

SAsSEn, S. (2007). Una sociología de la globalización. Buenos Aires: Katz edit.

United Nations (2015). World Urbanization Prospects. The 2014 Revision, New York: Department of Economic and Social Affairs, Population Division. Recuperado de https://esa.un.org/unpd/wup/publications/files/wup2014-highlights.pdf

ZAAR, M. (2011). Agricultura urbana: algunas reflexiones sobre su origen e importancia actual. Revista bibliográfica de geografía y ciencias sociales, 16(944), 742-798 Recuperado de http://www.ub.edu/geocrit/b3w-944. htm 


\section{ANEXOS}
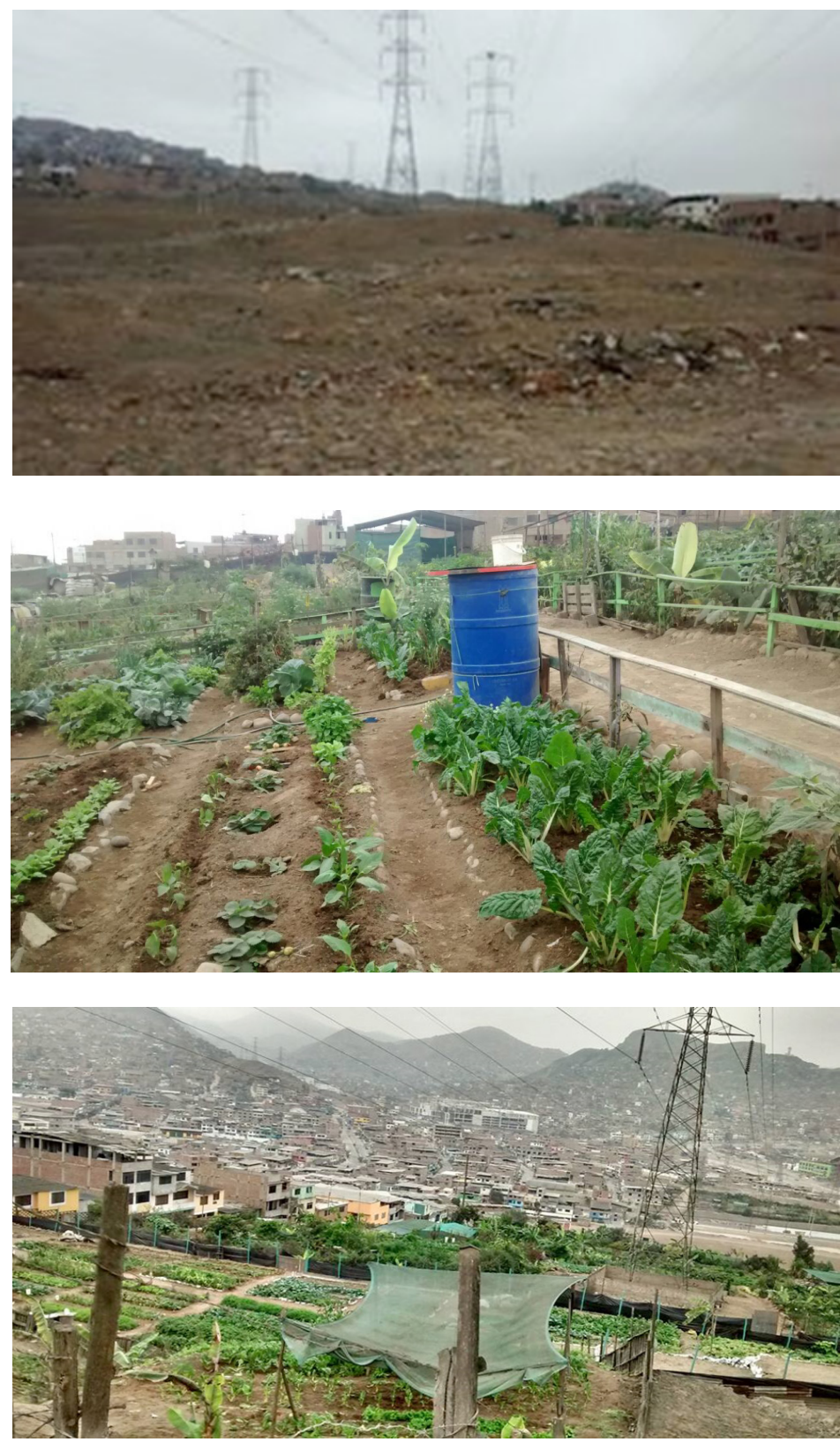

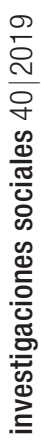

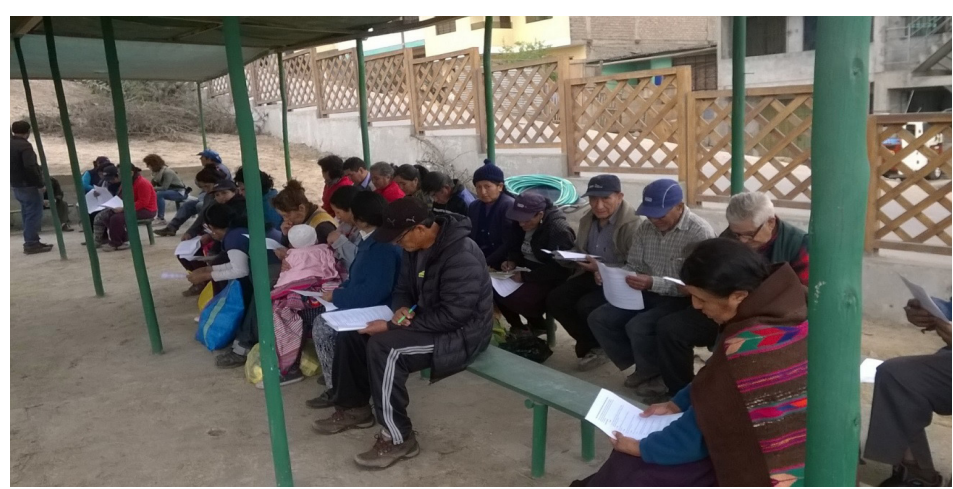

FOTO 1.

Espacio del tendido de los cables de alta tensión de REP.

FОTO 2.

Huerto de San Juan de Miraflores.

FOTO 3.

Huertos de Villa María de Triunfo.

FОTO 4.

Capacitación de la Municipalidad en los huertos de Villa María del Triunfo. 